\title{
KAJIAN SEMIOTIK DAN ETNOPEDAGOGI DALAM RUMPAKA TEMBANG SUNDA CIANJURAN
}

\author{
D. Nurfajrin Ningsih ${ }^{1}$ Helmi Husnul Hotimah ${ }^{2}$ \\ ${ }^{1}$ Universitas Suryakancana \\ ${ }^{2}$ Universitas Suryakancana
}

\begin{abstract}
ABSTRAK
Kearifan budaya lokal dapat dijadikan sebagai landasan pendidikan karakter, maka sekiranya kearifan budaya lokal dapat dimanfaatkan dalam dunia pendidikan. Tembang Sunda Cianjuran merupakan kearifan budaya lokal Cianjur yang memiliki nilai estetis, dan dapat dijadikan sebagai tuntunan pendidikan. Menurunnya eksistensi tembang Sunda Cianjuran khususnya di lingkungan generasi remaja saat ini dikhawatirkan dapat memberi pengaruh negatif. Berdasarkan latar belakang tersebut penelitian ini bertujuan untuk mendeskripsikan kajian semiotik dan etnopedagogi dalam rumpaka tembang Sunda Cianjuran. Metode yang digunakan dalam penelitian ini adalah metode deskriptif. Teknik yang digunakan untuk memperoleh data yaitu teknik dokumentasi dengan instrumen kartu data. Dari hasil penelitian disimpulkan bahwa (1) Keseluruhan makna yang diperoleh dari kajian semiotik dengan cara pembacaan heuristik dan pembacaan hermeneutika dalam tembang Maskumambang dan tembang Panambih Nimang adalah nasihat bagi seorang anak untuk menyayangi, menghormati dan berbakti terhadap orang tua khususnya kepada ibu; (2) Rumpaka tembang Maskumambang dan tembang Panambih Nimang mengandung nilai-nilai etnopedagogi yang berasal dari nilai budaya Sunda meliputi: Catur Jatidiri Insan, Moral Kemanusiaan, Gapura Panca Waluya dan Prilaku Nyunda Tri-silas.
\end{abstract}

Kata Kunci : rumpaka tembang Sunda Cianjuran, semiotik, dan etnopedagogi

\section{PENDAHULUAN}

$\mathrm{T}$ embang Sunda Cianjuran telah diakui oleh halayak bahwa secara estetis maupun secara filosofis tembang Sunda Cianjuran memiliki nilai yang luhur. Menurut Ischak (2006: 7) nilai-nilai dalam tembang dapat memberikan tuntunan dan pendidikan moral serta dapat memperhalus budi pekerti. Disamping itu rumpaka tembang Sunda Cianjuran memiliki kualitas yang baik dalam segi tema, tata bahasa, juga dalam makna yang terdapat dalam setiap rumpakanya. Meskipun demikian tembang Sunda Cianjuran tidak dapat terhindar dari persaingan budaya 
asing (modern). Persaingan itu mengakibatkan tembang Sunda Cianjuran kurang diminati dan dikhawatirkan dapat memberi pengaruh negatif terhadap tembang Sunda Cianjuran, salah satunya terjadi penurunan eksistensi Tembang Sunda Cianjuran di dalam masyarakat Cianjur khususnya dilingkungan generasi muda.

Peranan pendidikan dalam konteks kebudayaan merupakan hal yang penting, karena salah satu fungsi pendidikan dalam kebudayaan itu sendiri untuk mewariskan nilai-nilai kemanusiaan yang berasal dari budaya bangsa. Salah satu yang dapat dijadiakan sebagai sumber pendidikan yaitu kebudayaan yang lahir dan berkembang di lingkungan sekitar yang saat ini lebih dikenal sebagai sebutan kearifan budaya lokal. Maka dari itu revitalisasi pendidikan melalui kearifan budaya lokal dianggap perlu salah satunya dengan mengembangkan potensi wujud budaya lokal Cianjur melalui tembang Sunda Cianjuran yang dianggap efektif menjadi salah satu sumber pendidikan karakter.

Penelitian yang relevan dengan penelitian ini yaitu penelitian etnopedagogi yang telah dilakukan oleh Maulida, dkk (2014) yang mendeskripsikan struktur lirik tembang Sunda Cianjuran, interpretasi isi lirik tembang sunda Cianjuran, dan nilai etnopedagogi lirik tembang Sunda Cianjuran. Adapun penelitian semiotik tentang pupuh oleh Dayanti (2014) didalamnya membahas mengenai analisis semiotik yang mendeskripsikan pembacaan heuristik dan hermeneutik tembang Macapat Pupuh Asmarandana dalam Serat Witaradya 2 Karya Raden Ngabehi Ranggawarsita. Kebaruan penelitian yang dilakukan kali ini yaitu terletak pada penggabungan kajian semiotik dan kajian etnopedagogi dalam rumpaka tembang Sunda Cianjuran yaitu tembang Maskumambang dan tembang Panambih Nimang.

Tembang Sunda Cianjuran memiliki nilai klasik dan ciri khas tersendiri sebagai kebudayaan lokal yang rumpakanya dapat dikaji sebagai karya sastra berjenis puisi. Riffaterre (dalam Pradopo, 2007: 3) mengemukakan bahwa untuk menganalisis semiotik perlu dilakukan pembacaan heuristik dan pembacaan hermeneutik. Pembacaan heuristik adalah heuristik merupakan pembacaan karya sastra puisi berdasarkan sistem semiotik tingkat pertama (konvensi bahasa) dalam pembacaan heuristik teks dipandang tidak baku artinya teks dapat dinaturalisasikan guna menjelaskan arti bahasa secara normatif sehingga dapat memperjelas arti teks karya sastra, sedangkan pembacaan hermeneutik adalah merupakan pembacaan karya sastra puisi berdasarkan sistem semiotik tingkat kedua (konvensi sastra) dalam pembacaan hermeneutik dilakukan pembacaan ulang secara mendalam guna untuk menafsirkan karya sastra sehingga dapat memperjelas makna yang terdapat dalam karya sastra puisi.

Pengkajian semiotik yang dilakukan dalam penelitian ini menimbulkan interpretasi isi rumpaka tembang Sunda Cianjuran yang dapat dikaitkan dengan proses kajian etnopedagogi. Menurut Sudaryat (2015: 120) istilah etnopedagogi berasal dari dua gabungan kata etno dan kata pedagogi. Kata etno berasal dari bahasa Yunani etos yang memiliki arti suku bangsa atau lokal. Sementara kata pedagogi memiliki arti ilmu pendidikan dan pengajaran. Itu artinya etnopedagogi merupakan praktik pendidikan berbasis kearifan budaya lokal sebagai sumber 
inovasi dalam bidang pendidikan berbasis budaya lokal. Kajian etnopedagogi dalam penelitian ini didasarkan pada nilai-nilai budaya Sunda sesuai dengan pendapat Suryalaga (dalam Sudaryat, 2015: 124130) yang meliputi 1) Catur Jatidiri Insan yaitu berorientasi kepada keunggulan manusia secara paripurna sebagai manusia unggul yang meliputi pengkuh agamana, luhur elmuna, jembar budayana, dan rancage gawena; 2) Moral Kemanusiaan Moral kemanusiaan yang menjadi pandangaan hidup orang sunda yaitu moral manusia terhadap tuhan, moral manusia terhadap pribadi, moral manusia terhadap manusia lainnya, moral manusia terhadap alam, moral manusia terhadap waktu, moral manusia dalam mengejar kepuasan lahiriah dan batiniah; 3) Gapura Panca Waluya artinya gerbang lima kesempurna merupakan lima karakter yang menunjukkan keadaan manusia yang kukuh, berdedikasi tinggi dan berkomitmen seperti, cageur, bageur, bener, pinter, singer; dan 4) Prilaku Nyunda Tri-silas merupakan tiga sistem berinteraksi dalam lingkungan masyarakat yang mengandung kebersamaan yaitu silih asih, silih asah, silih asuh.

Tujuan penulisan artikel ini yaitu: 1) mendeskripsikan kajian semiotik dengan pembacaan heuristik dan hermeneutik dalam rumpaka tembang Sunda Cianjuran, dan 2) mendeskripsikan kajian nilai etnopedagogi dalam rumpaka tembang Sunda Cianjuran.

\section{METODE PENELITIAN}

$\mathrm{S}$ ecara umum metode penelitian diartikan sebagai cara ilmiah untuk mendapatkan data dengan tujuan dan kegunaan tertentu (Sugiyono, 2008: 3). Metode yang digunakan dalam penelitian ini yaitu metode deskriptif. Menurut Whitney (dalam Nazir, 2011: 54) metode deskriptif adalah pencarian fakta dengan interpretasi yang tepat. Dengan metode deskriptif akan diperloleh data faktual yang mendetail dengan melalui pencandraan gejala yang ada (Suryabrata, 2012: 76). Adapun dalam penelitian ini hal yang dideskripsikan adalah kajian semiotik dan kajian etnopedagogi dalam rumpaka tembang Sunda Cianjuran.

Data dalam penelitian ini adalah dua tembang Sunda Cianjuran yaitu tembang Maskumambang dan tembang Panambih Nimang. Teknik yang dilakukan untuk mengumpulkan kedua tembang tersebut dilakukan dengan teknik dokumentasi. Menurut Arikunto (2010: 274) teknik dokumentasi digunakan untuk mencari data mengenai hal-hal yang berupa catatan, transkrip, buku, surat kabar, majalah dan sebagainya. Instrumen yang digunakan dalam penelitian ini yaitu kartu data.

\section{HASIL DAN PEMBAHASAN}

$\mathrm{D}$ ari hasil proses pengumpulan dan pengolahan data kajian semiotik dan etnopedagogi dalam rumpaka tembang Sunda Cianjuran dapat didefinisikan sebagai berikut.

\section{Kajian Semiotik dalam Rumpaka Tembang Sunda Cianjuran}

Data kajian semiotik dalam penelitian ini mengenai rumpaka tembang Maskumambang dan rumpaka tembang Panambih Nimang. Dari kedua tembang tersebut dapat dianalis dengan kajian semiotik berdasarkan pembacaan heuristik dan hermeneutik.

\section{Pembacaan Heuristik dalam Rumpaka Tembang Sunda Cianjuran}

Pembacaan heuristik merupakan pembacaan berdasarkan struktur bahasanya 
atau secara semiotik tingkat pertama (konvensi kebahasaan). Selain itu pada pembacaan heuristik teks sastra dinaturalisasikan guna menjelaskan arti bahasa secara normatif sehingga dapat memperjelas arti teks sastra. Aspek tersebut digunakan sebagai landasan pembacaan pada kedua rumpaka tembang.

Penulis dibantu dengan kamus untuk penentuan arti (tanda) kebahasaan dalam pembacaan heuristik untuk menjelaskan arti bahasa secara normatif selain itu penentuan arti tembang Maskumambang dan Panambih Nimang dilakukan dengan diawali penomoran bait pada rumpaka, penyisipan kosakata dengan cara pemberian tanda kurung agar jelas dan mengganti kata-kata yang tidak baku menjadi baku sehingga arti teks sastra menjadi jelas. Pembacaan heuristik pada tembang Maskumambang dan tembang Panambih Nimang dapat diuraikan sebagai berikut.

\section{Pembacaan Heuristik dalam Rumpaka Tembang Maskumambang}

$$
\text { Pada rumpaka tembang }
$$

Maskumambang terdapat penyimpangan kata yang kehilangan imbuhan dan penyimpangan frasa yang dapat dilihat pada tabel berikut.

\section{Tabel 1. Pembacaan Heuristik dalam}

Rumpaka Tembang Maskumambang

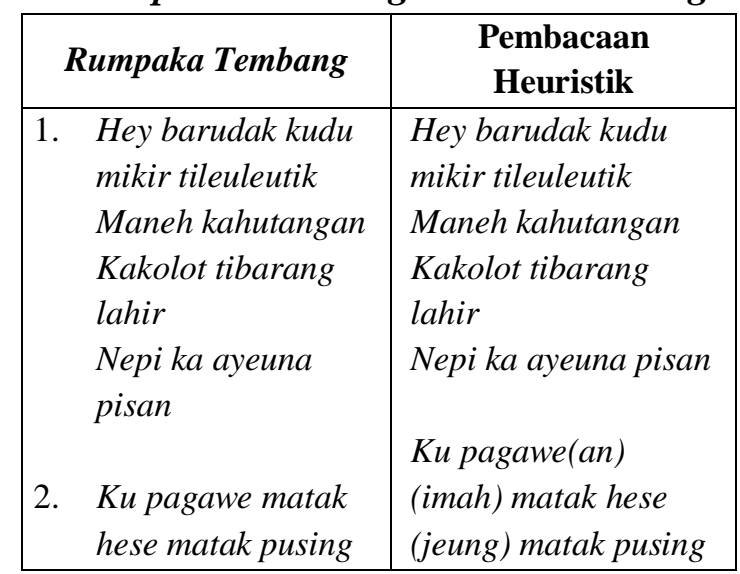

\begin{tabular}{|l|l|}
\hline $\begin{array}{l}\text { Suma won rugina } \\
\text { Kolot nya mere } \\
\text { rejeki }\end{array}$ & $\begin{array}{l}\text { Sumawon(a) rugina } \\
\text { Kolot (oge) nya mere } \\
\text { Dahar leueut } \\
\text { papakean }\end{array}$ \\
& $\begin{array}{l}\text { Dahar leueut (jeung) } \\
\text { papakean }\end{array}$ \\
& Maraneh teh kudu \\
3. & pisan boga pikir \\
pisan boga pikir & (Arek) mulang (keun) \\
Rek mulang tarima & tarima \\
Ka kolot rek males & Ka kolot (arek) \\
asih & (ngabales) asih \\
Dimana geus & Dimana (engke) geus \\
cumarita & cumarita \\
& (kahirupan sorangan) \\
\hline
\end{tabular}

Rumpaka tembang Panambih Nimang dengan pembacaan heuristik dapat diartikan sebagai berikut.

a) Pada bait pertama: hey anak-anak harus berfikir sedari kecil, kamu memiliki hutang, kepada orang tua sejak lahir, hingga sekarang.

b) Pada bait kedua: dengan pekerjaan (rumah) membuat susah (dan) pusing, apalagi ruginya, orang tua (juga) memberi rezeki, makanan minuman (dan) pakaian.

c) Pada bait ketiga: kamu semua sangat harus mempunyai pikiran, hendak membalas budi, hendak membalas budi, kepada orang tua (hendak) membalas kasih, dimana sudah bisa bercerita (kehidupan pribadi).

\section{Pembacaan Heuristik dalam Rumpaka Tembang Panambih Nimang}

Pada rumpaka tembang Panambih Nimang terdapat penyimpangan kata dan penyimpangan frasa yang dapat dilihat pada tabel berikut.

Tabel 2: Pembacaan Heuristik dalam Rumpaka Tembang Panambih Nimang 
Nama Penulis : Judul Artikel

Website : https://jurnal.umj.ac.id/index.php/penaliterasiEmail : penaliterasi@umj.ac.id

\begin{tabular}{|c|c|}
\hline Rumpaka Tembang & Pembacaan Heuristik \\
\hline $\begin{array}{l}\text { 1. Nelengnengkung, } \\
\text { nelengnengkung } \\
\text { geura gede geura } \\
\text { jangkung } \\
\text { geura nyiar elmu } \\
\text { luhung } \\
\text { geura mikanyaah } \\
\text { indung }\end{array}$ & $\begin{array}{l}\text { Nelengnengkung,neleng } \\
\text { nengkung } \\
\text { Geura (jadi) gede } \\
\text { (sareng) geura jangkung } \\
\text { geura nyiar elmu (anu) } \\
\text { luhung } \\
\text { geura mikanyaah (ka) } \\
\text { indung (anjeun) }\end{array}$ \\
\hline $\begin{array}{l}\text { 2. Lunta ka tungtung } \\
\text { Cipandan } \\
\text { dugi kana } \\
\text { babatarna } \\
\text { cinta na indung ka } \\
\text { anak } \\
\text { sesah milari } \\
\text { pantarna }\end{array}$ & $\begin{array}{l}\text { Lunta ka tungtung }(\text { di) } \\
\text { Cipandan } \\
\text { dugi kana (walungan) } \\
\text { (anu) babatarna } \\
\text { cinta na indung ka anak } \\
\text { (mah) } \\
\text { sesah milari (anu) } \\
\text { pantarna }\end{array}$ \\
\hline $\begin{array}{l}\text { 3. Ngalanglang } \\
\text { tungtung Cipandak } \\
\text { lepas ningal } \\
\text { sagarana } \\
\text { melangna indung } \\
\text { ka anak } \\
\text { langkung ti ka } \\
\text { salirana } \\
\text { 4eus subuh di mega } \\
\text { mendung } \\
\text { Isuk di tungtung } \\
\text { Cimanggu } \\
\text { Geus puguh waktu } \\
\text { ngakandung } \\
\text { Diuk nangtung teh } \\
\text { ngaganggu }\end{array}$ & $\begin{array}{l}\text { Ngalanglang (ka) } \\
\text { tungtung Cipandak } \\
\text { ningal(i) sagarana } \\
\text { le(u)pas } \\
\text { melangna indung ka } \\
\text { anak } \\
\text { langkung ti ka salirana } \\
\text { Geus subuh di mega } \\
\text { mendung } \\
\text { Isuk di tungtung } \\
\text { Cimanggu } \\
\text { Geus puguh waktu } \\
\text { (eukeur) ngakandung } \\
\text { (upami bade) diuk } \\
\text { (atanapi) } \\
\text { nangtung teh ngaganggu }\end{array}$ \\
\hline
\end{tabular}

Rumpaka tembang Panambih Nimang dengan pembacaan heuristik dapat diartikan sebagai berikut.

a) Pada bait pertama: nelengnengkung nelengnengkung, cepatlah (tumbuh) besar (dan) cepatlah tinggi, cepatlah mencari ilmu (yang) berbudi tinggi, cepatlah menyayangi (kepada) ibu(mu).

b) Pada bait kedua: pergi meninggalkan rumah ke ujung (di) Cipandan, sampai pada sungai (yang) bagian dangkalnya, kasih sayang ibu kepada anaknya, susah mencari (yang) sebanding.

c) Pada bait ketiga: meninjau sambil memeriksa (ke) ujung Cipandak, melihat lautan lepas, kekhawatiran ibu kepada anak, lebih dari kepada dirinya sendiri.

d) Pada bait keempat: Sudah subuh di kabut hujan, pagi di ujung Ciamnggu, sudah pasti saat waktu (sedang) mengandung, (kalau ingin) duduk (atau) berdiri itu sulit.

\section{Pembacaan Hermeneutik dalam Rumpaka Tembang Sunda Cianjuran}

Pembacaan Hermeneutik merupakan pembacaan karya sastra (puisi) berdasarkan konvensi sastra. Dalam pembacaan hermeneutik dilakukan pembacaan ulang secara mendalam guna untuk menafsirkan karya sastra sehingga dapat memperjelas makna yang terdapat dalam karya sastra puisi maka dari itu peneliti memberikan deskripsi-deskripsi arti tembang Maskumambang dan tembang Panambih Nimang agar arti teks menjadi lengkap dan mudah dimengerti.

\section{Pembacaan Hermeneutik dalam Rumpaka Tembang Maskumambang}

Tembang Maskumambang berwatak prihatin dan kesedihan. Ditijau dari pembacaan hermeneutik, tembang Maskumambang yang dianalisis ini menggambarkan sebuah keprihatinan orang tua saat membesarkan anaknya. Seorang anak hendaknya berpikir sedari kecil hingga sekarang bahwa dirinya telah merepotkan orang tua yang membesarkannya.

Dalam bait pertama pada rumpaka kedua terdapat kata kahutangan pada rumpaka berikut.

"Hey barudak kudu mikir tileuleutik Maneh kahutangan" 
Kata kahutangan artinya "memiliki hutang atau berhutang" hal itu menunjukan bahwa seorang anak berhutang kepada orang tuanya. kata Berutang disini bukan hanya memiliki arti berhutang uang yang harus dikembalikan tetapi menggambarkan seorang anak memiliki kewajiban untuk membalas budi yang telah diberikan oleh orang tua kepada anaknya, walaupun oarang tua memilki hati yang tulus memberikan segalanya demi membesarkan anaknya tanpa mengharapkan imbalan apapun.

Dalam bait kedua pada rumpaka ketujuh terdapat kolot nya mere rejeki pada rumpaka berikut.

"Kolot nya mere rejeki

Dahar leueut papakean”

Kata kolot nya mere rejeki artinya "orang tua memberi rejeki" menandakan bahwa orang tua menjadi salah satu jalan bagi anaknya mendapatkan rejeki dari Allah, itu artinya orang tua merupakan salah satu pintu rejeki bagi anaknya ketika Allah memberikan rejeki kepada hambanya.

Dalam bait ketiga pada rumpaka kedua belas terdapat kata cumarita dalam rumpaka berikut.

"Ka kolot rek males asih

Dimana geus cumarita"

Kata cumarita artinya "sudah bisa bercerita tentang kehidupan pribadi" (Danadibrata, 2009: 131). Kata tersebut menandakan bila seorang anak sudah bisa bercerita tentang kesuksesan dalam kehidupan pribadinya hendaklah seorang anak dapat membalas kasih sayang dan kebaikan orang tua, walau sebenarnya bahwa semua kasih sayang dan kebaikan yang telah orang tua berikan kepada anaknya tidak dapat terbalaskan.

Keseluruhan makna tembang Maskumambang ini menggambarkan bahwa anak memiliki hutang budi terhadap orang tuanya. Karena dari sejak lahir hingga saat ini orang tua telah membesarkan anaknya dengan segala pengorbanan. Kelak jika seorang anak telah tumbuh dewasa dan telah memiliki kesuksesan didalam hidup jangan sampai melupakan pengorbanan orang tua bahkan harus bisa berbakti. Hal yang harus diingat sesukses apapun seorang anak tidak akan mampu mengembalikan secara utuh apa yang telah diberikan orang tua kepada anaknya dari dulu hingga sekarang termasuk kasih sayang yang telah diberikan orang tua.

\section{Pembacaan Hermeneutik dalam Rumpaka Tembang Panambih Nimang}

Tembang Panambih Nimang yang dikaji memiliki watak sedih dan haru karena tembang tersebut menggambarkan kasih sayang seorang ibu terhadap anaknya. Dalam tembang ini digambarkan bagaimana seorang ibu memiliki kasih sayang yang tulus dan mengaharapkan halhal yang baik utuk anaknya.

Bait pertama pada rumpaka kesatu terdapat kata nelengnengkung dalam rumpaka berikut.

"Nelengnengkung, nelengnengkung" Kata nelengnengkung menandakan sebutan kesayangan dari seorang ibu kepada anaknya. Selain itu pada bait pertama pada rumpaka kedua sampai keempat yang menandakan harapan-harapan yaitu pada rumpaka berikut.

"geura gede geura jangkung
geura nyiar elmu luhung
geura mikanyaah indung",

Artinya "cepatlah cepatlah mencari ilmu dan berbudi luhur, cepatlah menyayangi ibumu" menandakan harapan seorang ibu untuk anaknya segera tumbuh dan mencari 
ilmu untuk membahagiakan ibu dengan ilmu tersebut, karena orang tua khususnya ibu akan sangat senang dan bangga jika anaknya berpengetahuan tinggi.

Dalam bait kedua pada rumpaka ketujuh dan kedelapan terdapat rumpaka sebagai berikut.

"cinta na indung ka anak sesah milari pantarna"

Artinya "susah mencari kasih sayang yang sama atau sebanding dengan kasih sayang seorang ibu kepada anaknya" menandakan kasih sayang seorang ibu kepada anak yang benar-benar tulus dan sejujur-jujurnya sehingga dapat diartikan bahwa sangat susah mencari kasih sayang yang sebanding dengan kasih sayang seorang ibu kepada anaknya.

Dalam bait ketiga pada rumpaka kesebelas dan kedua belas terdapat rumpaka sebagai berikut.

"melangna indung ka anak

langkung ti ka salirana”

Artinya "kekhawatiran ibu terhadap anaknya melebihi kekhawatiran seorang ibu terhadap dirinya sendiri" hal itu menandakan bahwa seorang ibu lebih menyayangi dan menkhawatirkan anaknya dibandingkan dengan dirinya sendiri dan seorang ibu akan benar-benar mengutamakan anaknya untuk hidup dengan baik dan layak dibandingkan memikirkan dirinya sendiri bahkan seorang ibu rela mempertarukan nyawa saat melahirkan anaknya.

Dalam bait ke empat pada rumpaka kelima belas dan keenam belas terdapat rumpaka sebagai berikut.

"geus puguh waktu ngakandung

diuk nangtung teh ngaganggu”
Artinya "pengorbanan ibu melawan rasa tidak nyaman saat mengandung" hal ini menandakan ketika seorang ibu mengandung anaknya selama sembilan bulan mengalami berbagai perjuangan dan pengorbanan, namun seorang ibu tidak memperdulikan hal yang dia alami, bagi dirinya yang terpenting adalah memastikan kondisi anaknya (bayi) yang dia kandung dalam keadaan baik-baik saja. Hal itu menunjukan betapa dalamnya kasih sayang seorang ibu terhadap anaknya.

Keseluruhan makna tembang Panambih Nimang menggambarkan tentang dalamnya kasih syang dari seorang ibu terhadap anaknya, tidak ada kasih sayang yang dapat sebanding dengan kasih sayang seorang ibu terhadap anaknya, bahkan seorang ibu lebih menyayangi anaknya dibandingkan dengan dirinya sendiri. Harapan-harapan yang baik akan selalu menjadi doa yang dipanjatkan seorang ibu untuk anaknya kelak agar anaknya bisa tumbuh dengan baik dan menjadi orang yang berilmu dan berbudi luhur. Maka dari itu sudah seharusnya seorang anak menghormati, menyayangi dan dapat berbakti kepada orang tua terlebih kepada ibunya dengan sepenuh hati.

\section{Kajian Etnopedagogi dalam Rumpaka Tembang Sunda Cianjuran}

Data penelitian dalam kajian etnopedagogi merupakan rumpaka tembang Maskumambang dan rumpaka tembang Panambih Nimang. Dari hasil analisis kedua rumpaka tembang tersebut mengandung nilai-nilai etnopedagogi yang bersumber pada nilai-nilai budaya Sunda yang meliputi 1) Catur Jatidiri Insan; 2) Moral Kemanusiaan; 3) Gapura Panca Waluya; dan 4) Prilaku Nyunda Tri-silas. Kajian etnopedagogi dalam rumpaka 
tembang tersebut diuraikan sebagai berikut.

\section{Kajian Etnopedagogi dalam Rumpaka Tembang Maskumambang}

Dalam rumpaka

Maskumambang pada bait pertama, rumpaka kesatu termasuk nilai etnopedagogi Moral Kemanusiaan dapat dilihat dalam rumpaka berikut.

"Hey barudak kudu mikir tileuleutik"

Kata kudu mikir memiliki arti "harus berpikir" yang termasuk dalam poin moral manusia terhadap pribadi karena berpikir termasuk kedalam sikap manusia dengan diri pribadi sebagai individunya sendiri.

Pada bait pertama, rumpaka ketiga sampai pada rumpaka keempat termasuk nilai etnopedagogi Moral Kemanusiaan dapat dilihat dalam rumpaka berikut.

"Kakolot tibarang lahir

Nepika ayeuna pisan"

Rumpaka diatas memiliki arti "kepada orang tua dari sejak lahir sampai saat ini" termasuk kedalam moral manusia terhadap waktu dahulu dan waktu sekarang.

Pada bait kedua, rumpaka ke tujuh samapai pada rumpaka kedelapan termasuk nilai etnopedagogi Moral Kemanusiaan dapat dilihat dalam rumpaka berikut.

"Kolot nya mere rejeki

Dahar leueut papakean"

Rumpaka diatas memiliki arti "orang tua ya memberi rejeki, makan minum pakaian" termasuk dalam poin moral manusia dalam mengejar kepuasan lahiriah dan batiniah.

Pada bait ketiga, rumpaka kesembilan termasuk dalam nilai etnopedagogi Moral Kemanusiaan dapat dilihat dalam rumpaka berikut.

"Maraneh teh kudu pisan boga pikir"
Rumpaka di atas artinya "kalian sangat harus mempunai pikiran" yang termasuk dalam poin moral manusia terhadap pribadi karena sikap berpikir termasuk kedalam sikap manusia dengan diri pribadi sebagai individunya.

Pada bait ketiga, rumpaka kesepuluh termasuk dalam nilai etnopedagogi Gapura Panca Waluya (gerbang lima kesempurnaan) dapat dilihat dalam rumpaka berikut.

"rek mulang tarima"

Rumpaka di atas artinya "hendak membalas budi" yang termasuk dalam Gapura Panca Waluya poin bageur (keadaan atau karakter manusia yang baik hati).

Pada bait ketiga, rumpaka kesebelas termasuk dalam nilai etnopedagogi Prilaku Nyunda Tri-silas dapat dilihat dalam rumpaka berikut.

"Ka kolot rek males asih"

Rumpaka di atas artinya "kepada orang tua hendak membalas kasih sayang" termasuk dalam Prilaku Nyunda Tri-silas poin silih asih (tingkah laku yang memperhatikan rasa kasih sayang yang tulus).

Pada bait ketiga, rumpaka kedua belas termasuk dalam nilai etnopedagogi Catur Diri Insan dapat dilihat dalam rumpaka berikut.

\section{"Dimana geus cumarita"}

Rumpaka di atas artinya "dimana sudah bisa bercerita tentang kesuksesan pribadi" yang termasuk dalam Catur Diri Insan poin rancage gawena (gabungan keseluruhan dari kecerdasan intelektual, kecerdasan emosional dan kecerdasan sosial sehingga dapat beretos kerja tinggi, berprestasi, berprilaku kreatif, inovatif yang bisa menyesuaikan diri dengan perkembangan zaman). 
Nama Penulis : Judul Artikel

Website : https://jurnal.umj.ac.id/index.php/penaliterasiEmail : penaliterasi@umj.ac.id

Kajian Etnopedagogi dalam Rumpaka Tembang Panambih Nimang

Dalam tembang Panambih Nimang pada bait pertama, rumpaka kedua termasuk nilai etnopedagogi Gapura Panca Waluya (gerbang lima kesempurnaan) dapat dilihat dalam rumpaka berikut.

"geura gede geura jangkung"

Rumpaka di atas artinya "cepatlah tumbuh besar dan tinggi" yang termasuk dalam Gapura Panca Waluya poin cageur (merupakan keadaan sehat, baik sehat jasmani maupun sehat rohani).

Pada bait pertama, rumpaka ketiga termasuk dalam nilai etnopedagogi Catur Diri Insan dan termasuk ke dalam Gapura Panca Waluya dapat dilihat dalam rumpaka berikut.

"geura nyiar elmu luhung"

Rumpaka di atas artinya "cepatlah mencari ilmu dan berbudi tinggi" termasuk dalam Caur Diri Insan poin jembar budayana (merupakan kecerdasan emosi, berwawasan luas, arif bijaksana, tidak gagap akan budaya, tidak kehilangan jatidiri yang manusiawi dan agamis serta menghargai multietnis dan multikultur) dan termasuk kedalam Gapura Panca Waluya poin pinter (memiliki ilmi pengetahuan).

Pada bait peratama, rumpaka keempat termasuk dalam nilai etnopedagogi Prilaku Nyunda Tri-silas dapat dilihat dalam rumpaka berikut.

"geura mikanyaah indung"

Rumpaka di atas artinya "cepatlah menyayangi ibu" yang termasuk dalam Prilaku Nyunda Tri-silas poin silih asih (tingkah laku yang memperhatikan rasa kasih sayang yang tulus).

Pada bait kedua, rumpaka keujuh sampai pada rumpaka kedelapan termasuk dalam nilai etnopedagogi Prilaku Nyunda
Tri-silas dapat dilihat dalam rumpaka berikut.

"cinta na indung ka anak sesah milari pantarna”

Rumpaka di atas artinya "susah mencari cinta yang sebanding seperti cintanya ibu kepada anaknya" yang termasuk dalam Prilaku Nyunda Tri-Silas poin silih asih (tingkah laku yang memperhatikan rasa kasih sayang yang tulus).

Pada bait ketiga, rumpaka sebelas sampai pada rumpaka kedua belas termasuk dalam nilai etnopedagogi Prilaku Nyunda Tri-Silas dan Gapura Panca Waluya (gerbang lima kesempurnaan) dapat dilihat dalam rumpaka berikut.

"melangna indung ka anak

langkung ti ka salirana”

Rumpaka di atas artinya "khawatirnya seorang ibu kepada anaknya melebihi kekhawatiran terhadap dirinya sendiri" yang termasuk dalam Prilaku Nyunda TriSilas poin silih asih (tingkah laku yang memperhatikan rasa kasih sayang yang tulus) dan termasuk dalam Gapura Panca Waluya poin bageur (keadaan atau karakter manusia yang baik hati).

\section{KESIMPULAN}

$\begin{array}{rrr}\text { erdasarkan hasil penelitian mengenai } \\ \text { kajian } & \text { semiotik dan etnopedagogi } \\ \text { dalam rumpakar tembang }\end{array}$ Maskumambang dan rumpaka tembang Panambih Nimang dapat disimpulkan sebagai berikut.

1. Kajian semiotik dalam rumpaka tembang Maskumambang dan tembang Panambih Nimang dilakukan dengan pembacaan heuristik dengan cara memunculkan kembali imbuhan 
serta kosakata yang dihilangkan dengan memberikan tanda kurung agar jelas dan mengganti kata-kata yang tidak baku menjadi baku. Sedangkan pembacaan hermeneutik dilakukan dengan pembacaan ulang karya sastra secara mendalam guna untuk menafsirkan karya sastra. Keseluruhan makna yang terdapat dalam tembang Maskumambang dan tembang Panambih Nimang adalah nasihat bagi seorang anak untuk menyayangi, menghormati dan berbakti terhadap orang tua khususnya kepada ibu.

2. Pengkajian semiotik yang dilakukan menimbulkan interpretasi isi rumpaka tembang Sunda Cianjuran yang dapat dikaitkan dengan proses kajian etnopedagogi. Kajian etnopedagogi dalam rumpaka tembang Maskumambang dan tembang Panambih Nimang didasarkan pada nilai-nilai budaya Sunda. Berdasarkan hasil pengkajian kedua rumpaka tembang tersebut mengandung nilainilai etnopedagogi yaitu: a) Catur Jatidiri Insan meliputi rancage gawena dan jembar budayana; b) Moral Kemanusiaan meliputi moral manusia terhadap pribadi, moral manusia terhadap waktu serta moral manusia dalam menejar kepuasan lahiriah dan batiniah; c) Gapura Panca Waluya meliputi cageur, bageur dan pinter; dan d) Prilaku Nyunda Tri-silas meliputi silih asih.

\section{REFERENSI}

Arikunto, Suharsimi. 2010. Prosedur Penelitian Suatu Pendekatan Praktik. Jakarta: PT RINEKA CIPTA.
Dayanti, Tri. 2014. "Analisis Semiotik Tembang Macapat Pupuh Asmarandana dalam Serat Witaradya 2 Karya Raden Ngabehi Ranggawarsita" Dalam Jurnal Program Studi Pendidikan Bahasa dan Sastra Jawa Universitas Muhammadiyah Purwprejo. [ofline] Volume. 05 (05). 9 halaman. Tersedia:

http://docplayer.info/51611571Analisis-semiotik-tembang-macapatpupuh-asmarandana-dalam-seratwitaradya-2-karya-raden-ngabehiranggawarsita.html [18 Januari 2018]

Ischak, C. Aah. 2006. Mengenal Tembang Sunda Cianjuran. Cianjur : Liebe Book Pres.

Maulida, Siti Maryam, Yayat Sudaryat dan Iskandarwassid. 2014. "Lirik tembang Sunda Cianjuran (Kajian Struktural Dinamik dan Etnopedagogi)" Dalam Loka Bahasa [online], Volume 5, 9 halaman. Tersedia: ejournal.upi.edu/index.php/lokabasa/a $\underline{\text { rticle/view/3163/2183 }} \quad[06$ April 2017]

Nazir, Moh. 2011. Metode Penelitian. Bogor: Penerbit Ghalia Indonesia.

Pradopo, Rachmat Djoko. 2007. Pengkajian Puisi Analisis Strata Norma dan Analisis Struktural dan Semiotik. Yogyakarta: Gadjah Mada University Press.

Sudaryat, Yayat. 2015. Wawasan Kesundaan. Bandung: Jurusan Pendidikan Bahasa Daerah. 
Nama Penulis : Judul Artikel

Website : https://jurnal.umj.ac.id/index.php/penaliterasiEmail : penaliterasi@umj.ac.id

Sugiyono. 2008. Metode Penelitian

Pendidikan. Bandung: Alfabeta.

Suryabrata, Sumadi. 2012. Metodologi

Penelitian. Jakarta: PT RajaGrafindo

Persada. 